\title{
Violência de Gênero, Participação Política e Ações Afirmativas Concretização da Igualdade Jurídica Para a Mulher
}

\author{
Miriam Freitas Elias \\ Mestre em Ciências Criminais pela PUCRS (2014), Dele- \\ gada de Polícia Civil do Rio Grande do Sul desde 2008. \\ mlfelias@yahoo.com.br
}

\section{Resumo}

Este artigo aborda os aspectos que desencadeiam a violência de gênero contra a mulher na sociedade brasileira, bem como as conquistas feministas no âmbito legislativo, em busca da igualdade de participação política da mulher. A complexidade das relações interpessoais que perpassam a violência de gênero contra a mulher em uma sociedade patriarcal exige múltiplas ações estatais, no âmbito legislativo, educacional e cultural, como forma de diminuir a discriminação sofrida pelas mulheres nas esferas pública e privada. Por essa razão, ações afirmativas como as cotas eleitorais estabelecidas pela Lei no 9.504/97 fazem-se necessárias como instrumentos reguladores na redução de desigualdades entre homens e mulheres. Mediante revisão bilbiográfica de autores feministas, buscar-se-á demonstrar que a lei referida se coaduna com o Princípio da Igualdade.

Palavras-chave: Violência de gênero contra a mulher. Princípio da Igualdade. Políticas públicas. Ações afirmativas. Cotas eleitorais.

\section{GENDER VIOLENCE, POLITICS PARTICIPATION AND AFFIRMATIVE ACTIONS: materializing legal equality for women}

\begin{abstract}
The article examines the triggering aspects of gender violence against women in brazilian's society, as well as feminist achievements in legislation, searching for politics equal participation of women. The complexity of interpersonal relations which involves gender violence against women in a patriarchal society requires multiple state actions, legislative, educational and cultural, as a way of decreasing the discrimination of women on private and public sphere. Therefore, affirmative actions as electoral
\end{abstract}


quotas provided for in Law n. 9.504/97 are needed as a regulatory instrument for decreasing inequality between men and women. Through literature review of feminist's authors, it aimes to demonstrate that the referred law is consistent with the Equality Principle.

Keywords: Gender violence against women. Equality principle. Public policies. Affirmative actions. Electoral quotas.

\section{Sumário}

1. Introdução. 2. Violência de gênero contra a mulher. 3. Feminismo e Participação Política. 4. Ações Afirmativas e Princípio da Igualdade. 5. Lei oo 9.504/1997 e as cotas eleitorais. 6. Conclusão. 


\section{INTRODUÇÃO}

O conceito de gênero foi construído socialmente visando a compreender as relações estabelecidas entre homens e mulheres, baseadas nos papéis que cada um assume na sociedade e nas relações de poder entre eles. Vive-se numa sociedade humana que é histórica, que muda conforme o padrão de desenvolvimento da produção, dos valores e normas sociais (Vincensi, 2011, p. 18).

A luta feminista é, pois, uma luta pela democracia, que deve nascer da igualdade entre homens e mulheres e evoluir para a igualdade entre todos os seres humanos, suprimindo as desigualdades de classe, etnia e gênero.

Indicadores como mortalidade materna, gravidez na adolescência e reduzida participação feminina no Legislativo e no mercado de trabalho deixaram o Brasil no 80ㅜ (octogésimo) lugar na lista de 138 nações avaliadas pelo Índice de Desigualdade de Gênero (IDG), o qual capta as desvantagens das mulheres e as perdas de potencial de desenvolvimento em saúde reprodutiva, empoderamento, autonomia e atividade econômica (PROGRAMA..., 2010).

No Brasil, a Política Nacional de Enfrentamento à Violência, desde 2003, incorporou ações que se destinam à prevenção, assistência e garantia dos direitos das mulheres nas áreas de educação, assistência social, saúde, segurança, cultura e justiça.

Em janeiro de 2003 foi constituída a Secretaria Especial de Políticas para as Mulheres (SPM), da Presidência da República. Em 2004, a partir das diretrizes definidas na $1^{\text {a }}$ Conferência Nacional de Políticas para as Mulheres (CNPM), foi elaborado o Plano Nacional de Políticas para as Mulheres (PNPM) que propõe a promoção da igualdade de gênero (Vincensi, 2011, p. 30-31). 
Esse artigo aborda a importância da inclusão política das mulheres, como meio adequado de suscitar no âmbito político as demandas feministas em sua totalidade (incluindo os diferentes femininos: mulher branca, negra, índia, pobre, lésbica, etc.) e diminuir, gradativamente, a violência de gênero. Para tanto, aborda a relevância de ações afirmativas como o estabelecimento de cotas eleitorais aos partidos políticos, para a candidatura de mulheres, e a adequação dessas ações ao princípio constitucional da igualdade.

\section{VIOLÊNCIA DE GÊNERO CONTRA A MULHER}

Violência de gênero diz respeito a "las creencias, actitudes, sentimientos, valores y conductas que marcan la diferencia entre hombres y mujeres a través de un proceso de construcción social” (Alencar-Rodrigues; Cantera, 2012, p. 117). Resulta, portanto, da socialização dos indivíduos:

Os modelos que se constroem, então, tanto do homem quanto da mulher deverão corresponder às funções esperadas desses sujeitos aos quais foram atribuídos papéis específicos. Enquanto o homem aparece através de uma figura forte, disciplinadora, isento de instintos, emoções e sensibilidade, a mulher vai surgir através de uma imagem sensível, fiel, honesta, instintiva, generosa, perspicaz, garantindo-se essa ambivalência através de um pacto de dominação, na medida em que tanto um como o outro incorpora em suas práticas, o discurso enunciado desse domínio expresso nos valores contrários fragilidade-força (Álvares, 2003, p. 3).

Salvo em populações isoladas e que não conseguiram disseminar seus pensamentos, a mulher sempre foi, de alguma forma, discriminada; suas opiniões não eram relevantes para aqueles que representavam a coletividade e que, de fato, conduziam os rumos do progresso econômico e político. 
Essa é a essência do paternalismo, ou autoridade paterna do homem: "Esse patriarcado caracteriza-se pelo predomínio de valores masculinos, fundamentados em relações de poder exercidas por complexos mecanismos de controle social que oprimem e marginalizam as mulheres" (Masi; Amato, 2009, p. 24).

A construção social dos sexos atribui diferentes espaços de poder para homens e mulheres, nos quais a mulher em geral ocupa lugares de menor empoderamento, e, muitas vezes, de subalternidade:

En efecto, las normas sociales que gobiernan la relación conyugal se hacen explícitas a través de los argumentos del conflicto y éstas se expresan, en términos generales, como un ejercicio irrestricto de la voluntad del hombre y un control sobre el comportamiento de la mujer. Una expresión paradigmática de la relación de subordinación es "pedir permiso al marido" (Agoff, 2009, p. 405).

O conceito de gênero foi popularizado por Joan Scott como sendo um "elemento constitutivo das relações sociais, baseado em diferenças percebidas entre os sexos; [...] uma forma primária de significação das relações de poder" e passou a ser utilizado para se compreender as complexas relações de poder entre homens e mulheres. A utilização da categoria gênero introduz nos estudos sobre violência contra as mulheres um novo termo para discutir tal fenômeno social: violência de gênero (Scott, 1988, p. 42-44 apud Celmer, 2007).

A violência de gênero ocorre na sociedade como fruto de construções relacionais entre homens e mulheres inseridos numa cultura patriarcal. Entende-se por patriarcado a organização sexual hierárquica da sociedade tão necessária ao domínio político. Alimenta-se do domínio masculino na estrutura familiar (esfera privada) e na lógica organizacional das instituições políticas (esfera pública) construída a partir de um modelo masculino de dominação de “arquétipo viril” (Costa, 1999, p. 4). 
Esses modelos de papéis sociais determinam uma relação predominantemente hierárquica entre os sexos, por meio dos pressupostos do sistema patriarcal: "Os códigos de poder do paterfamilias exploram, em essência, a existência de uma 'natureza masculina' e outra 'feminina', com essa assimetria sexual sendo legitimada, no âmbito das relações concretas, como elemento universal e sendo tratado como "natural”" (Álvares, 2003, p. 4).

Hansel (2005, p. 52) disserta que a violência contra a mulher se constrói principalmente no âmbito cultural:

Por terem as mulheres o monopólio da função reprodutiva e a capacidade de amamentação, a elas se atribui, com exclusividade, toda a responsabilidade pela criação dos filhos e organização do lar. No entanto, a reserva de papéis diferenciados ao homem e à mulher é uma construção cultural, que é reforçada através da transgeracionalidade também pelas mulheres que criam suas filhas desde que nascem com brinquedos imitando réplicas do espaço doméstico, e os filhos autônomos e independentes. [...] Na prática, a violência e a discriminação se retroalimentam, porque a submissão é passada através de legados familiares, e a rainha do lar ocupa uma posição subordinada e de submissão, pois deve obediência ao marido, dono e senhor da casa.

Essa naturalidade com que a sociedade encara os papéis sociais de homens e mulheres faz com que as próprias mulheres sirvam de algozes de outras: "Los estereotipos rígidos de género, en particular el de la sumisión y obediencia al marido, y el mandato fatalista expresado en la frase 'es tu cruz' que se transmite de mujer a mujer en la familia contribuyen a naturalizar la violencia y a significarla como destino natural de muchas mujeres” (Agoff, 2009, p. 409). 
Costa explica que existe poder em todas as relações interpessoais, e que esse poder se mantém porque os vários atores - tanto os dominadores quanto os dominados - "aceitam” as versões da realidade social que negam a existência de desigualdades. Segundo a autora, essa aceitação é construída pelos mecanismos de socialização (Costa, 1999, p. 3).

$\mathrm{Na}$ sociedade sempre existem indivíduos que exercem poder mais ou menos arbitrário sobre outros, ora de maneira brutal e violenta, ora de forma sutil e oculta. Múltiplas relações de poder perpassam, caracterizam e constituem o corpo social: "é nessa perspectiva que se constrói a dominação do homem sobre a mulher, mesclado e reproduzido com as teias do patriarcalismo" (Branco; Pinto, 2010, p. 3).

O domínio patriarcal, portanto, está presente no cotidiano da sociedade, tanto no âmbito privado quanto no público, não sendo necessário que se externize por discriminações violentas. Em geral, a dominação ocorre simbolicamente, pelo restrito acesso das mulheres ao poder político.

A estereotipia dos papéis sociais reservados a homens e a mulheres continua a delimitar os parâmetros de subjetivação e de segregação nas relações de gênero, em que as demandas sociais contemporâneas continuam trazendo, ao senso comum, a ideia de homens educados para serem provedores e independentes, sem considerar a possibilidade de virem a ter de dividir responsabilidades e protagonismos com suas parceiras: "a ideologia que reproduzimos é a mesma que nos produz enquanto protagonistas e coadjuvantes desta mesma história em comum - o discurso não é aquilo que fala, mas aquilo que permite falar e que leva a calar" (Winck; Strey, 2007, p. 253).

A cristalização dos papéis masculinos e femininos na sociedade se potencializa por meio de histórias e mitos, como o contido no livro Gênesis da Bíblia (visão judaico-cristã). Essas delimitações vão-se tornando ver- 
dades inquestionáveis, como que santificadas, naturalizando a aceitação cultural do "lugar" da mulher e, por consequência, legitimando a relação de hierarquia e poder entre os gêneros:

A compreensão das relações de gênero implica que sejam entendidas como construção social baseada na diferenciação biológica dos sexos, expressa através de relações de poder e subordinação, representada pela discriminação de funções, atividades, normas e condutas esperadas para homens e mulheres em cada sociedade (Silva, 2011, p. 5).

Silva ressalta que para desconstruir as relações de gênero, é preciso modificar concepções de masculino e feminino, como que dotadas de adjetivos específicos. Não há estereótipos de gêneros, mas sim seres humanos racionais e individuais em suas características: "não existe apenas uma mulher ou um homem, mas sim, diferentes construções simbólicas de papéis que são flexíveis e mutáveis ao longo do tempo” (Silva, 2011, p. 7).

Chantal Mouffe (1999, p. 34) também salienta esse aspecto, ou seja, que não há sentido na discussão sobre a igualdade e diferença entre uma categoria "homem” e outra “mulher”, pois ambas não são homogêneas, ao contrário, há "multiplicidade de relações sociais onde a diferença sexual está construída sempre de diversos modos, e onde a luta contra a subordinação tem que ser estabelecida de formas específicas e diferenciais”.

Nesse universo de "femininos", contudo, há um denominador comum: a menor expressividade das demandas dos grupos de mulheres no âmbito do poder político. Mulheres brancas, negras ou índias de qualquer classe social ou orientação sexual não têm representatividade proporcional nas câmaras legislativas, ou nos cargos de chefia, tanto no âmbito privado quanto no público, em qualquer dos três poderes que se analise. 
Por conseguinte, mesmo que não se possa falar um "mulheres" como um grupo homogêneo, pode-se falar em "femininos" como um coletivo que busca uma fala mais significativa e empoderada no âmbito político brasileiro e mundial.

A luta feminista volta-se contra a cultura dominante que interpreta as relações de gênero de uma maneira assimétrica e desfavorável à igualdade de direitos. Não apenas a autocompreensão cultural dos homens quanto ao valor das mulheres, contudo, prejudica a igualdade de direitos femininos em nossa sociedade, mas também a própria autocompreensão cultural das mulheres quanto à contribuição que elas deram à cultura comum está igualmente distante de contar com o devido reconhecimento (Habermas, 2002, p. 238).

\section{FEMINISMO E PARTICIPAÇÃO POLÍTICA}

A segunda metade do século 19 e o início do século 20 foi um período de grandes mobilizações de mulheres, com diversas reivindicações, tais como o direito de organização sindical, de entrar nas universidades, de se filiar aos partidos políticos, contra condições de trabalho extremamente precárias e jornadas que chegavam a 16 horas diárias e, principalmente, pelo direito ao voto (Hansel, 2005, p. 20).

O movimento político feminista articulou-se em torno do enfoque da igualdade entre os gêneros (representada inicialmente pelo direito ao voto), porém a igualdade formal conquistada em uma sociedade com domínio patriarcal não resultou, automaticamente, em igualdade material. Ao contrário, o poder masculino permanece oprimindo, utilizado-se de formas mais sutis (mas nem por isso menos eficientes).

Somente após a conquista dos direitos civis - a partir dos anos 30 - é que o movimento feminista percebeu a necessidade de estabelecer um processo de transformação mais amplo, em que o próprio conceito de igualdade fosse questionado: 
Essa será a tônica do movimento de mulheres dos anos 80. [...] A conquista da igualdade jurídica, que por várias décadas foi meta do movimento feminista, não tem conseguido incorporar as mulheres nesse modelo de cidadania dominante. Cada vez mais avança a consciência da necessidade do estabelecimento de políticas públicas que possam estimular e mesmo garantir uma maior integração feminina, à estrutura de poder, ao mundo da política formal (Costa, 1999, p. 1).

No Brasil, o processo de formação do movimento feminista ocorreu, em grande parte, no contexto da história dos partidos de esquerda na luta contra a ditadura militar. Os movimentos feministas envolveram pesquisadoras, acadêmicas e militantes que atuavam dentro de um mesmo projeto político, qual seja, o de confrontar e de contestar as discriminações e as relações de poder existentes na sociedade, denunciando a opressão patriarcal e capitalista vivida pelas mulheres, sobretudo na família e no mercado de trabalho (Narvaz; Koller, 2007, p. 218).

O marco histórico das conquistas feministas deu-se a partir da Revolução Industrial, perpassou o movimento feminista da década de 80 e teve seu ápice, no Brasil, com a promulgação da Carta Magna de 1988, a qual legitimou a igualdade entre os gêneros. A Constituição Federal consagrou o direito de a mulher dirigir sua própria vida, como forma de reconhecer sua dignidade enquanto ser individual (Masi; Amato, 2009, p. 26).

Nancy Fraser (2007, p. 293) explica que a segunda onda do movimento feminista expandiu seus interesses para abranger a luta das mulheres negras e lésbicas (novos movimentos sociais). Numa primeira expansão do pós-guerra, o feminismo ampliou seu imaginário, incluindo a luta da esquerda ao "sustentarem uma visão expandida da política que incluísse 'o pessoal' [...] expandiram as fronteiras de contestação para além da redistribuição socioeconômica - para incluir o trabalho doméstico, a sexualidade e a reprodução”. Nessa fase, o imaginário feminista lutava 
por um ideal de redistribuição, que foi substituído por um ideal de reconhecimento (necessidade de reconhecer a “diferença”) com o declínio da utopia da nova esquerda.

As ideias antieconomicistas foram ressignificadas e incorporadas em um novo imaginário político que colocou questões culturais em primeiro plano: "capturado por esse imaginário culturalista, o feminismo reinventou-se como política de reconhecimento [...] foi atraído para a órbita da política de identidade”, que visa mais à valorização da diferença que à promoção da igualdade (Fraser, 2007, p. 293).

Com a mudança político-econômica de o Estado do bem-estar social para o neoliberalismo globalizante, o feminismo teve de ressignificar seu imaginário novamente, de uma politica de reconhecimento para uma política de representação, que sintetizasse as duas anteriores, em uma política transnacional:

[...] importantes correntes do feminismo estão desafiando o quadro de demandas políticas do Estado territorial. Da forma como elas vêem, esse quadro é um grande veículo de injustiça, pois reparte o espaço político de maneira a bloquear a contestação, pelas mulheres, das forças que as oprimem. [...] o quadro do Estado territorial é auto-isolante; a arquitetura do sistema inter-Estados protege a partilha do espaço político que ela institucionaliza, efetivamente excluindo a tomada de decisão democrática transnacional nas questões de justiça de gênero. [...]

Sob o abrangente slogan "direitos das mulheres, direitos humanos", feministas ao redor do mundo estão conectando as lutas contra as práticas patriarcais locais a campanhas para reformar o direito internacional (Fraser, 2007, p. 304).

A nova fase da política feminista reenquadra o problema da justiça de gênero, com maior preocupação com as injustiças que estão a ela interligadas: a má distribuição dos bens econômicos e o não reconhecimento jurídico. Segundo Fraser (2007, p. 304), as feministas estão combatendo 
uma "meta injustiça" que a autora chama de mau enquadramento: "o mau enquadramento surge quando o quadro do Estado territorial é imposto a fontes transnacionais de injustiça”.

Ao confrontar o mau enquadramento, esta fase do feminismo torna visível uma terceira dimensão da justiça do gênero, que é a da representação:

Representação não é apenas uma questão de assegurar voz política igual a mulheres em comunidades políticas já constituídas. Ao lado disso, é necessário reenquadrar as disputas sobre justiça que não podem ser propriamente contidas nos regimes estabelecidos. Logo, ao contestar o mau enquadramento, o feminismo transnacional está reconfigurando a justiça de gênero como um problema tridimensional, no qual redistribuição, reconhecimento e representação devem ser integrados de forma equilibrada (Fraser, 2007, p. 305).

Para alcançar a igualdade material e alterar os processos e estruturas que reduzem as mulheres a uma posição subordinada, foi incorporado ao movimento feminista o conceito de empoderamento (surgido com os movimentos de direitos civis nos Estados Unidos, nos anos 70, por meio da bandeira do poder negro). Empoderamento, conceitua Costa (1999, p. 7), “é o mecanismo pelo qual as pessoas, as organizações, as comunidades tomam controle de seus próprios assuntos, de sua própria vida, de seu destino, tomam consciência da sua habilidade e competência para produzir e criar e gerir".

O feminismo precisou empreender vários assaltos, sofrendo forte oposição, para fazer valer seus objetivos legais e políticos. Para Habermas (2002, p. 235), no entanto, as políticas feministas pela igualdade de direitos, nas sociedades ocidentais, têm seguido um modelo dialético entre igualdades jurídica e factual: “competências jurídicas iguais criam espaço 
para liberdades de ação que se podem utilizar diferencialmente e que, portanto, não fomentam a igualdade factual das situações de vida ou das posições de poder”.

Logo, a violência de gênero, por estar arraigada na cultura das sociedades, precisa ser transformada no âmbito educacional, complementado as mudanças legislativas, que, por si sós, são inócuas.

A política liberal buscou viabilizar - mediante a legislação - a conquista de status às mulheres, garantindo igualdade de oportunidades para postos de trabalho, prestígio social, educação formal, poder político, etc., todavia intervenções padronizadas e externas às deliberações sociais acabaram por evidenciar e desigualdade no tratamento factual:

A política socioestatal, sobretudo no âmbito do direito social, trabalhista e de família, reagiu a isso com regulamentações especiais, relativas à gravidez ou maternidade, ou então a encargos sociais em casos de divórcio. Nesse ínterim, não apenas as exigências liberais irresolvidas, mas também as consequiências ambivalentes de programas socioestatais implementados com êxito tornaram-se objeto da crítica feminista - por exemplo, os riscos decorrentes do trabalho, que cresceram por causa das compensações sociais acima mencionadas, a presença excessiva de mulheres nas camadas de remuneração mais baixas, o problemático "bem-estar da criança”, a crescente "feminização" da pobreza de modo geral, etc. (Habermas, 2002, p. 236).

A legislação inovadora, para ter efetividade, necessita modificar as ideologias que cristalizam a cultura. As mulheres precisam perceber-se como sujeitos de direitos autônomos (empoderamento), a fim de transformar a maneira como os homens as percebem e valorizam:

Este conjunto de reglas e ideales está en consonancia con el ideal identitario femenino. Es posible afirmar que la identidad de la mujer está fuertemente supeditada a su participación en redes de relaciones y en estructuras de valores y normas que refuerzan su imagen como miembro de un grupo "indivisible" - la familia - en detrimento de una 
autoconcepción como sujeto de derechos. [...] Estos atributos son no sólo ideales de autorrealización sino también garantes del reconocimiento y valoración social (Agoff, 2009, p. 411).

Coelho e Carloto (2007, p. 396) trazem a informação de que na Conferência Internacional de População e Desenvolvimento (CIPD), realizada no Cairo, em 1994, foi destacado que os indicadores de saúde das mulheres só se modificariam efetivamente na medida em que "a população masculina também demonstrasse movimentos de mudança em seus padrões de comportamento”.

$\mathrm{Na}$ Conferência foi enfatizada a necessidade de maior participação dos homens na vida familiar - com o propósito de reequilibrar as relações de poder - para atingir maior igualdade de gênero.

\section{AÇÕES AFIRMATIVAS E PRINCÍPIO DA IGUALDADE}

A despeito de o princípio da isonomia estar presente nas Constituições brasileiras desde 1824, durante muito tempo a igualdade permaneceu apenas no campo formal. A Constituição Federal de 1988, no campo das ações afirmativas, previu expressamente incentivos ao mercado de trabalho da mulher - como parte dos direitos sociais - e a reserva percentual de cargos e empregos públicos para deficientes.

Historicamente, as políticas públicas brasileiras se caracterizaram pela adoção de uma perspectiva social, com medidas assistencialistas contra a pobreza, concebidas tanto por políticos de esquerda quanto de direita. Atualmente, alguns movimentos sociais passaram a exigir uma mudança de postura diante de questões sociais, étnicas, econômicas e regionais, e a adoção de medidas específicas para sua solução, aumentando a importância jurídica e política das ações afirmativas (Moreira, 2008, p. 5). 
O Brasil é signatário de vários acordos, tratados e convenções nacionais e internacionais, pelas quais assume o compromisso de erradicar a discriminação, os estereótipos de gênero e a violência contra as mulheres, além de promover a igualdade de gênero e a autonomia feminina. Por essa razão, foi incluído o recorte transversal de gênero na formulação e na instituição de políticas públicas do país, demonstrando a crescente relevância dessa questão para o programa de governo (Narvaz; Koller, 2007, p. 218).

Vilas-Bôas (2003, p. 70) conceitua discriminação contra a mulher como toda distinção, exclusão ou restrição baseada no sexo e que tenha por objeto ou resultado

[...] prejudicar ou anular o reconhecimento, gozo ou exercício pela mulher, independentemente de seu estado civil, com base na igualdade do homem e da mulher, dos direitos humanos e liberdades fundamentais nos campos político, econômico, social, cultural e civil ou em qualquer outro campo.

Assim, o Direito deve servir como um instrumento tanto para impedir a formação de desigualdades quanto para promover a igualdade, pois uma sociedade verdadeiramente democrática, apoiada no conceito de cidadania, é aquela que fornece oportunidades verdadeiramente iguais para o desenvolvimento da pessoa humana (Lima, 2009, p. 8).

A fundamentação de igualdades materiais, salienta Lubenow (2010, p. 125), em conformidade com a teoria democrática de Habermas, ocorre numa situação de disputa política em torno do que precisa ser reconhecido, isto é, uma luta pelo reconhecimento jurídico de necessidades e exigências normativas peculiares em relação ao conjunto de toda a comunidade jurídica, na qual os grupos interessados procuram apresentar aos demais as experiências particulares de exclusão social, discriminação e carências de sua realidade, como forma de convencimento sobre a necessidade de um tratamento jurídico formalmente diferenciado. 
Em 2003, a fim de impulsionar e articular, de forma transversal, a institucionalização das questões de gênero tais como previstas na plataforma de governo, foi criada, pela Presidência da República, a Secretaria Especial de Políticas para as Mulheres (SPM), com status de Ministério. A SPM objetiva desenvolver ações conjuntas com todos os Ministérios e Secretarias Especiais, a fim de estabelecer políticas públicas específicas para as mulheres, construindo as condições necessárias para a sua plena cidadania (Narvaz; Koller, 2007, p. 219).

Para transformar a igualdade formal prevista na Constituição Federal em igualdade material, é necessária a atuação estatal, por meio de normas jurídicas, políticas públicas e ações afirmativas:

Transpor a fronteira do formal, do deôntico, para a realidade é possível [...] a incumbência do Estado é dar o primeiro passo rumo à efetivação dos direitos fundamentais, com a ampliação do conceito do princípio da igualdade do plano formal para o material, quer seja através de políticas públicas efetivas, ações afirmativas para minimizar as disparidades existentes em determinadas minorias, quer seja através da conscientização da importância da cidadania (Lima, 2009, p. 9).

As ações afirmativas têm sido criadas como resposta do Estado às demandas sociais, como forma de reduzir as desigualdades existentes no país. Elas são expressão do compromisso público de atuação do Estado em prol da igualdade material dos cidadãos:

Estas ações constituem medidas especiais e temporárias que, buscando remediar um passado discriminatório, objetivam acelerar o processo de igualdade, com o alcance da igualdade substantiva por parte de grupos vulneráveis, como as minorias étnicas e raciais, as mulheres, dentre outros grupos. As ações afirmativas, enquanto políticas compensatórias adotadas para aliviar e remediar as condições resultantes de um passado discriminatório, cumprem uma finalidade pública decisiva ao projeto, que é a de assegurar a diversidade e a pluralidade social (Piovesan, 2007, p. 221). 
Para alcançar a igualdade jurídica no plano material, segundo Fraser, ${ }^{1}$ é necessário eliminar as disparidades sociais e as diferenças de gênero:

A condição necessária para igualdade participativa é que as desigualdades sociais sejam eliminadas. Isso não significa necessariamente que todos devam ter exatamente a mesma renda, mas requer um tipo de igualdade que é inconsistente com relações de dominação geradas sistemicamente [...] Democracia política requer substantiva igualdade social.

Young (2006, p. 140), ao criticar o modelo de democracia deliberativa, em razão da necessidade de defender a maior inclusão política nos processos democráticos de representação dos grupos sub-representados (minorias), especialmente quando esses grupos estão sujeitos a desigualdades estruturais, enfatiza o problema da "representação na democracia deliberativa":

No contexto dessas sociedades (complexas e pluralistas) são muito frequentes as queixas que apontam o caráter excludente das normas de representação. As pessoas muitas vezes reclamam que os grupos sociais dos quais fazem parte ou com os quais têm afinidade não são devidamente representados nos organismos influentes de discussões e tomadas de decisão, tais como legislaturas, comissões e conselhos, assim como nas respectivas coberturas dos meios de comunicação.

A autora salienta que ativistas dos movimentos de mulheres de diversos países reivindicam a participação feminina nos corpos legislativos, pois "legislaturas ocupadas majoritariamente por homens não podem representar devidamente as mulheres” (Young, 2006, p. 140). Em resposta a essa reivindicação do movimento feminista, alguns governos têm adotado medidas voltadas a proporcionar maior presença feminina nos órgãos

1 Rethinking the public sphere, p. 123 (apud Lubenow, 2010, p. 121). 
legislativos, geralmente determinando que os partidos incluam uma certa proporção de mulheres nas suas listas de candidatos, como ocorreu no Brasil com a publicação da Lei no 9.504/1997.

Em relação às objeções à prática de ações afirmativas como a de estabelecimento de cotas eleitorais, ora analisada, Young (2006, p. 143) destaca que, apesar de as mulheres terem diferentes identidades, etnias, religiões, culturas, etc., o que as torna um movimento heterogêneo (similar aos demais grupos de minorias), ainda assim as cotas são uma medida essencial para a inclusão política. Principalmente porque a representação política não consiste em substituição, mas sim em

[...] um relacionamento diferenciado entre atores políticos engajados num processo que se estende no espaço e no tempo. [...] estar posicionado similarmente no campo social gera uma perspectiva social cuja inclusão na discussão pública pode ser promovida por processos de representação de grupos. Conceitualizo uma distinção entre interesses, opiniões e perspectivas e identifico seus respectivos papéis na participação política. [...] nas grandes sociedades de massa a representação e a participação se requerem uma à outra para que haja uma política plenamente democrática.

O representante, pois, não tem a capacidade de retratar a identidade de qualquer outra pessoa, tampouco a identidade coletiva de um eleitorado. Assim, é inevitável que haja uma diferença e uma separação entre representante e eleitores, mas isso não desconfigura a importância da representação feminina no parlamento, mesmo existindo uma pluralidade de femininos.

Sem representação política numericamente adequada e proporcional, as mulheres enfrentam dificuldades de levar seus interesses e opiniões à pauta de decisões políticas (torná-los prioridades) e, consequentemente, influenciar programas, projetos e políticas públicas: 
Poucos negariam que os membros de grupos sociais estruturais menos privilegiados estão sub-representados na maioria das democracias contemporâneas. [...] Na maior parte dos sistemas políticos, as mulheres ocupam uma pequena proporção dos cargos públicos eleitos, bem como estão relativamente pouco presentes nas posições de poder e influência na vida pública e privada de modo geral. [...] Uma forma importante de promover maior inclusão de membros dos grupos sociais sub-representados se dá por meio de dispositivos políticos destinados especificamente a aumentar a representação de mulheres, pessoas da classe trabalhadora, minorias raciais ou étnicas, castas desfavorecidas, etc. Assim, esquemas como cotas em listas partidárias, representação proporcional, cadeiras parlamentares reservadas e delimitação de distritos eleitorais especiais, entre outros, têm sido propostos e implementados para promover a representação de grupos (Young, 2006, p. 169).

A Lei nº 9.504/1997 configura-se em uma ação afirmativa por via de normatização jurídica. Sua criação evidencia o conteúdo democrático do princípio da igualdade jurídica, bem como um caminho viável para a correção da desigualdade de oportunidades políticas e sociais entre os gêneros.

O impacto promovido pela ação política do movimento feminista é responsável pela gradativa mudança de mentalidade que vem se processando na sociedade, juntamente com a execução de políticas públicas que têm contribuído para a transformação da condição social das mulheres nas últimas décadas.

Segundo Ferreira $(2004$, p. 1), a simples análise da presença das mulheres no Legislativo em diferentes países da América Latina, do Caribe, dos Estados Unidos e da África reflete a desigualdade de gênero presente na sociedade, o que evidencia a necessidade de uma ação afirmativa como a reserva de cotas eleitorais. 


\section{LEI № 9.504/1997 E AS COTAS ELEITORAIS}

No Brasil, a história da participação da mulher no Parlamento tem como marco inicial a conquista do direito ao voto, que se deu em 1932, como resultado da luta contínua do movimento sufragista, que emergiu no Brasil em 1919. Até a década de 70, no entanto, o quadro de exclusão das mulheres do poder não sofreu muitas modificações. Somente a partir do final da década de 80 é que a situação começou a se modificar, em virtude do crescimento industrial e do aumento significativo da participação feminina no mercado de trabalho (Ferreira, 2004, p. 1).

Nesse período instalou-se o processo de redemocratização do país, encorajando as mulheres a se organizarem politicamente e inserirem na nova Carta Constitucional seu direito à igualdade.

Em 1988 o percentual de mulheres parlamentares no Brasil, em todos os âmbitos - federal, estadual e municipal - estava em torno de 6,2\%. Com o intuito de buscar a igualdade de fato entre homens e mulheres na participação política, foi criada, em 1995 , a Lei $n^{\circ} 9.100$, que estabelecia que 20\%, no mínimo, dos candidatos apresentados pelos partidos políticos ou coligações para eleições proporcionais deveriam ser do sexo feminino. Posteriormente, a Lei $\mathrm{n}^{\mathrm{o}}$ 9.504, de 30 de setembro de 1997, aumentou o percentual para 30\% (Almeida; Ferreira, 2007, p. 5.732).

A Lei $\mathrm{n}^{\circ} 9.504 / 97$, em seu artigo $10^{\circ}, \S^{\circ}$, estabelece regra que a doutrina e a jurisprudência convencionaram denominar cota eleitoral de gênero. Esse artigo foi alterado pela reforma eleitoral de 2009 - Lei no 12.034/09 - e a redação atual do dispositivo dispõe que: "Do número de vagas resultante das regras previstas neste artigo, cada partido ou coligação preencherá o mínimo de 30\% (trinta por cento) e o máximo de $70 \%$ (setenta por cento) para candidaturas de cada sexo”. 
Essa alteração foi oportuna, uma vez que fortaleceu a norma sob enfoque, modificando o comando normativo de "deverá preencher" para “preencherá”. Tal alteração reforçou o entendimento segundo o qual o cálculo dos percentuais de $30 \%$ e $70 \%$ devem levar em conta o número de registros de candidaturas efetivamente requeridos por partidos e coligações, e não o número previsto em abstrato pelo artigo $10^{\circ}$, caput e $\$ 1^{\circ}$ da referida lei. Esse é o entendimento esposado pelo Tribunal Superior Eleitoral, a exemplo do Recurso Especial Eleitoral $n^{0}$ 78.432/PA.

Assim, com a alteração, se uma agremiação partidária não atingir número suficiente de candidatos homens e mulheres, em observância à cota eleitoral de gênero, não poderá preencher com candidatos de um sexo as vagas destinadas ao sexo oposto. Admitir tal atitude significaria esvaziar o conteúdo da norma, violando os princípios que ela busca assegurar.

$\mathrm{Na}$ hipótese de resultado fracionário, ao aplicar-se os percentuais estatuídos na lei, o $\S^{\circ}$ do artigo $10^{\circ}$ estipula que deve ser "desprezada a fração, se inferior a meio, e igualada a um, se igual ou superior”.

Almeida e Ferreira discutem a adequação da referida lei à teoria da democracia deliberativa de Habermas, seguindo a teoria da legitimação do discurso e da tomada de decisão democrática. Para esses autores, a lei configura uma ação afirmativa de gênero, e se coaduna com a necessária inserção dos cidadãos na discussão pública (representatividade), no caso, das cidadãs mulheres, que são mais da metade da população, porém não correspondem a 50\% dos membros das casas legislativas:

Ao estabelecer um mínimo de $30 \%$ de vagas para ambos os sexos, a Lei 9.504 de 1997, estaria cumprindo o papel de garantir liberdade, igualdade e abertura, fundamentais para a situação ideal de diálogo defendida por Habermas. $\mathrm{O}$ abismo existente no Legislativo entre o número de homens e o número de mulheres seria superado, tendo em vista que a quantidade de indivíduos de ambos os sexos se aproximaria, gerando 
uma maior igualdade. A idéia habermasiana de incluir na representação todos os destinatários das normas jurídicas também seria respeitada, tendo em vista que as mulheres não estariam presentes apenas nos espaços públicos, mas teriam uma maior representatividade nos fóruns oficiais (Almeida; Ferreira, 2007, p. 5.737).

A importância da representação parlamentar das mulheres por outras mulheres, conforme Young (2006, p. 168), ocorre em razão da perspectiva semelhante que compartilham, na qual se possibilita trazer à discussão legislativa assuntos pertinentes a interesses de grupos de mulheres:

[...] representar um interesse ou uma opinião geralmente envolve promover certos desdobramentos específicos no processo de tomada de decisões, ao passo que representar uma perspectiva geralmente significa promover certos pontos de partida para a discussão. A partir de uma determinada perspectiva social um representante coloca certos tipos de questões, relata certos tipos de experiência, retoma uma determinada linha de narrativa histórica ou expressa um certo modo de olhar as posições de outrem. Isso contribui decisivamente para a inclusão de diferentes pessoas no processo de tomada de decisões e chama a atenção para possíveis efeitos das políticas propostas sobre os diferentes grupos.

É notório que os membros de grupos sociais menos privilegiados estão sub-representados na maioria das democracias contemporâneas. A desigualdade socioeconômica tem como consequência a desigualdade política, em que as demandas desses grupos não são atendidas com a presteza das solicitações emanadas dos grupos com influência na sociedade.

$\mathrm{Na}$ maior parte dos sistemas políticos as mulheres ocupam uma pequena proporção dos cargos públicos eleitos, o que diminui suas posições de poder e influência na vida pública e privada de modo geral. Essa marginalização política "frustra as promessas de igualdade política e de oportunidades que estão na base dos princípios democráticos” (Young, 
2006, p. 170). A resposta para alterar tal marginalização, segundo Young, é a inclusão política por intermédio de medidas como a criação de cotas em listas partidárias.

Assim sendo, ações afirmativas que propiciem a representação de mulheres em órgãos legislativos por meio de cotas em listas de candidatos dos partidos políticos, favorecem a representação de interesses e perspectivas diferenciadas, complementando o processo democrático.

\section{CONCLUSÃO}

O conceito de gênero foi adotado como categoria epistemológica, em substituição ao sexo, a fim de desvincular a discussão das desigualdades existentes entre homens e mulheres dos conceitos ligados à Biologia, e, consequentemente, demonstrando suas raízes culturais.

Os estereótipos de gênero construídos ao longo da História da humanidade, com algumas variações de sociedade para sociedade, cristalizam desigualdades de oportunidades no âmbito político e social entre mulheres e homens. Em decorrência das raízes socioculturais da discriminação contra a mulher, a violência de gênero precisa ser combatida em diversos âmbitos, por ações educacionais, culturais e legislativas.

O movimento feminista, ao longo de sua história, combateu o patriarcado reivindicando o espaço das mulheres na vida pública e a defesa de seus direitos e de sua integridade física e moral na vida privada. As conquistas constitucionais e legislativas de direitos para as mulheres refletem o resultado dessa luta. Para que a igualdade jurídica seja efetivada, no entanto, é preciso ultrapassar a previsão legal, por meio de políticas públicas e ações afirmativas que modifiquem o quadro de desigualdades entre os gêneros. 
A Lei $n^{0}$ 9.504/1997 configurou-se em ação afirmativa normativa que visa à inclusão política das mulheres, buscando aumentar a participação feminina nas casas legislativas, por meio da exigência de cotas eleitorais aos partidos políticos. As cotas eleitorais não ferem o princípio constitucional da igualdade porque visam exatamente a reverter a histórica desigualdade de tratamento das mulheres na sociedade brasileira.

Para alcançar a igualdade material, as mulheres precisam efetivar sua inclusão política, trazendo para a pauta legislativa as demandas dos diferentes grupos de mulheres (brancas, negras, índias, pobres, lésbicas, etc.), bem como provocando a discussão na esfera pública de seus interesses e necessidades. Somente com sua efetiva participação política poderão as mulheres alcançar a cidadania de forma plena e independente.

\section{REFERÊNCIAS}

AGOFF, M. C. La aberta competencia entre el reconocimiento jurídico y la valoración social: El caso de la violencia de pareja. Civitas, Porto Alegre, v. 9, n. 3, p. 402-417, set./dez. 2009.

ALENCAR-RODRIGUES, R.; CANTERA, L. Violencia de Género en la Pareja: Una Revisión Teórica. Psico, v. 43, n. 1, p. 116-126, jan./mar. 2012.

ALMEIDA, F. A.; FERREIRA, R. A. J. Ação afirmativa de gênero e crítica feminista à democracia deliberativa: racionalidade e neutralidade no discurso democrático? In: CONGRESSO NACIONAL DO CONPEDI, 16., 2007, Belo Horizonte. p. 5.727-5.745. Disponível em: <http://www.conpedi.org.br/ manaus/arquivos/anais/bh/fernanda_andrade_almeida2.pdf $>$. Acesso em: 24 jul. 2013.

ÁLVARES, M. L. M. A questão de gênero e a violência doméstica e sexual. 2003. Disponível em: <http://www.ufpa.br/projetogepem/administrator/questaodegenero.pdf . Acesso em: 18 jul. 2013. 
BRANCO, J. M. A.; PINTO, K. C. Lei Maria da Penha e violência sexual doméstica contra a mulher: mecanismo de poder no processo de vitimação do feminino. 25 ago. 2010. Disponível em: <http://www.webartigos.com/artigos/ lei-maria-da-penha-e-violencia-sexual-domestica-contra-a-mulher/45602/>. Acesso em: 29 jul. 2013.

CELMER, E. G. Violência conjugal contra a mulher: refletindo sobre gênero, consenso e conflito na Justiça Criminal. Ártemis, v. 6, p. 26-37, jun. 2007.

COELHO, S. M. P. F.; CARLOTO, C. M. Violência doméstica, homens e masculinidades. Revista Textos\&Contextos, Porto Alegre, v. 6, n. 2, p. 395-409, jul./ dez. 2007.

COSTA, A. A. A. Gênero, poder e empoderamento das mulheres. Salvador: Neim; Ufba, 1999. Disponível em: <http://www.agende.org.br/docs/File/dados_pesquisas/feminismo/Empoderamento\%20-\%20Ana\%20Alice.pdf>. Acesso em: 29 jul. 2013.

FERREIRA, M. Do voto feminino à lei de cotas: a difícil inserção das mulheres nas democracias representativas. Espaço Acadêmico, Maringá, n. 37, ano IV, jun. 2004. Disponível em: <http://www.espacoacademico.com. br/037/37cferreira.htm>. Acesso em: 25 jul. 2013.

FRASER, N. Mapeando a imaginação feminista: da redistribuição ao reconhecimento e à representação. Estudos Feministas, Florianópolis, n. 15, p. 291-308, maio/ago. 2007. Traduzido de Constellations, Oxford: Blackwell Publishing, v. 12 , n. 3, p. 295-307, 2005.

HABERMAS, J. A inclusão do outro - estudos de teoria política. São Paulo: Edições Loyola, 2002.

HANSEL, M. E. P. Dores \& amores: mulheres vítimas de violência doméstica. 2005. 71 f. Trabalho de Conclusão de Curso (Pós-Graduação em Psicologia Jurídica) - Universidade Luterana do Brasil, Canoas, RS, 2005.

LIMA, V. B. O. Ações afirmativas como instrumentos de efetivação do princípio da igualdade e do princípio da dignidade da pessoa humana. 2009. Disponível em: <http://www.fa7.edu.br/recursos/imagens/File/direito/ic/v_encontro/ acoesafirmativascomoinstrumentos.pdf $>$. Acesso em: 24 jul. 2013. 
LUBENOW, J. A. As críticas de Axel Honneth e Nancy Fraser à Filosofia Política de Jürgen Habermas. Veritas, v. 55, n. 1, p. 121-134, jan./abr. 2010. MASI, C. V.; AMATO, G. C. A estigmatização do gênero feminino em A Hora da Estrela: uma reflexão criminológica acerca da violência contra a mulher. Direito\&Justiça, v. 35, n. 1, p. 22-27, jan./jun. 2009.

MOREIRA, G. C. O princípio da igualdade nas ações afirmativas e a política de quotas. Âmbito Jurídico, Rio Grande, ano XI, n. 58, out. 2008. Disponível em: <http://www.ambito-juridico.com.br/site/index.php?n_link=revista_artigos_leitura\&artigo_id=3166>. Acesso em: 24 jul. 2013.

MOUFFE, C. Feminismo, cidadania e política democrática radical. In: Debate feminista. São Paulo: Cia. Melhoramentos, Edição Especial (Cidadania e Feminismo), 1999. p. 29-47.

NARVAZ, M. G.; KOLLER, S. H. A marginalização dos estudos feministas e de gênero na psicologia acadêmica contemporânea. Psico, v. 38, n. 3, p. 216-223, set./dez. 2007.

PIOVESAN, F. Ações afirmativas no Brasil: desafios e perspectivas. In: CAMARGO, Marcelo Novelino (Org.). Leituras complementares de constitucional. Direitos fundamentais. 2. ed. Salvador: Juspodivm, 2007.

PROGRAMA DAS NAÇÕES UNIDAS PARA O DESENVOLVIMENTO. PNUD. 2010. Programa das Nações Unidas para o Desenvolvimento. Índice do Desenvolvimento Humano. Disponível em: <HTTP://www.pnud.org.br/idh/>. SCOTT, Joan. Gender: a useful category of historical analysis. In: Gender and the Politics of History. New York. Columbia University Press, 1988. p. 42-44.

SILVA, C. A desigualdade imposta pelos papéis de homem e mulher: uma possibilidade de construção da igualdade de gênero. 2011. Disponível em: $<$ http://www.unifia.edu.br/projetorevista/artigos/direito/20121/desigualdade_imposta.pdf . Acesso em: 16 jul. 2013.

YOUNG, I. M. Representação política, identidade e minorias. Lua Nova, São Paulo, n. 67, p. 139-190, 2006. 
VILAS-BÔAS, R. M. Ações afirmativas e o princípio da igualdade. Rio de Janeiro: América Jurídica, 2003.

VINCENSI, J. G. Estratégias de enfrentamento das mulheres frente à violência intrafamiliar. 2011. 124 f. Dissertação (Mestrado em Serviço Social) - Pontifícia Universidade Católica do RGS, Porto Alegre, RS, 2011.

WINCK, G. E.; STREY, M. N. Percepções sobre o gênero em homens acusados de agressão. Psico, Porto Alegre, v. 38, n. 3, p. 246-253, set./dez. 2007.

Recebido em: $24 / 4 / 2014$

Aceito em: $14 / 8 / 2015$ 